\title{
Correspondence
}

\section{Anaesthesia fellowships in Canada}

To the Editor:

Our department has recently reviewed its Fellows' Program. This included a preliminary review of other programs offered at Canadian University Departments of Anaesthesia. The advertisement of positions available for interested applicants documents 106 positions across the country. Memorial University, Queen's University, and the University of Saskatchewan do not have positions at this time. The number of postgraduate fellows has increased considerably since 1992. Candidates tend to come from Great Britain, Australia, and most recently, Canada. This may reflect a change in the career options for graduates of Canadian programs. The general duties of fellows include clinical, research, teaching, and administrative opportunities that tend to vary among departments. Six departments conduct a performance review before completion of a fellowship.

Although there was some interest in ACUDA playing a role in regulating the activities of fellows across the country, the majority of departments felt this should remain a departmental concern. Programs in Ontario expressed concern about the future of their programs based on the impact of government cutbacks. In contrast, programs in western Canada were optimistic about their ability to maintain, and in some instances, expand their programs.

This information may be of assistance for those involved in the administration of programs or individuals who are considering applying for postgraduate fellowships in Anaesthesia.

David M. Ansley MD FRCPC

Department of Anaesthesia

Vancouver Hospital and Health Sciences Centre

\section{A simple method to decrease malposition of Robertshaw-type tubes}

To the Editor:

Double-lumen endotracheal tubes (DLTs) have become the lung separation technique of choice to provide one-lung ventilation during anesthesia for the majority of thoracic surgery cases." The plastic disposable Robertshaw-type tubes are by far the most commonly used DLTs. A left-sided tube is preferable for most cases requiring one-lung ventilation because the right-sided tube incurs the risk of inadequate right upper lobe ventilation. ${ }^{2}$ The DLT intubation procedure and cuff inflationdeflation manoeuvres are well known. ${ }^{1}$ The tube is introduced with cuffs deflated and, after rotation, advanced until most of it is inserted. A high incidence of malpositioning has been described with subsequent fibreoptic bronchoscopy. ${ }^{3}$ There are three possible gross malpositions: in too far on the left (both lumina in left main stem bronchus), out too far (both lumina in the trachea) and in or down the right main stem bronchus. Inflation and deflation of the left cuff while the left lumen is clamped create a breath sound differential diagnosis of tube malposition. ${ }^{1}$

We have been using a different strategy for Robertshaw DLT intubation with success. We select the size of tube based on the height and sex of the patient ${ }^{4}$ and coat the tube liberally with lubrication. We partially inflate the left cuff with one $\mathrm{mL}$ air, instead of introducing the DLT completely deflated. Advancement of the tube ceases when moderate resistance is met indicating that the tube has been firmly seated in the left mainstem bronchus. This technique does not cause difficulty in passing the vocal cords but prevents the introduction of both lumina in the left mainstem bronchus which is the most frequent malpositioning in our and others' experiences. The partially inflated left cuff prevents further passage of the right lumen into the left mainstem bronchus. The correct DLT position should always be confirmed fibreoptically after initial placement and positioning of the patient. ${ }^{3}$ In our experience, partial inflation of the left cuff has decreased the incidence of initial malpositioning of the Robertshaw-type DLTs from $30 \%$ to $<5 \%$

Alfredo Panadero MD PhD

María José Iribarren MD PhD

Ignacio Fernández-Liesa MD

Pablo Monedero MD PhD

Department of Anesthesiology and Critical Care

Clinica Universitaria. School of Medicine

University of Navarra

Palmplona (Spain)

\section{REFERENCES}

1 Benumof $J L$, Alfery $D D$. Anesthesia for thoracic surgery. In: Miller RD (Ed.). Anesthesia. New York: Churchill Livingstone, 1994, 1689-715.

2 Benumof JL, Partridge BL, Salvatierra C, Keating J. Margin of safety in positioning modern double-lumen endotracheal tubes. Anesthesiology 1987; 67: 729-38.

3 Alliaume B, Coddens $J$, Deloof $T$. Reliability of auscultation in positioning of double-lumen endobronchial tubes. Can J Anaesth 1992; 39: 687-90.

4 Hannallah MS, Benumof $J$, McCarthy PO, Liang $M$. Comparison of three techniques to inflate the bronchial cuff of left polyvinylchloride double-lumen tubes. Anesth Analg 1993; 77: 990-4.

5 Lieberman D, Littleford J, Horan T, Unruh H. Placement of left double-lumen endobronchial tubes with or without a stylet. Can J Anaesth 1996; 43: 238-42.

\section{Graduated compression stocking prevents hypotension during spinal anaesthesia}

To the Editor:

Since 1991, almost all patients under spinal anaesthesia have 